\title{
Subversión, coerción y consenso: violencia estatal en el Chile del siglo XX
}

Q Verónica Valdivia Ortiz de Zárate

Universidad Diego Portales, Chile.

veronicavaldiviaoz@gmail.com

Artículo recibido: 03 de junio de 2019. Aprobación final: 12 de diciembre de 2019.

\section{Resumen}

Este trabajo analiza la represión estatal en Chile, entre 1925 y el golpe de 1973. Su hipótesis sostiene que ella se relacionó con un conflicto político que la Constitución de 1925, y los acuerdos de 1932, no resolvieron, sin arribarse a reales consensos respecto al proyecto país, esto es, el papel del Estado, el carácter, amplitud y profundidad de los derechos sociales y la incorporación política de los partidos de izquierda, marxistas. Los dispositivos represivos estatales respondieron a un tipo de amenaza particular, legal-institucionalizada. Por ello, la coerción fue policial, de inteligencia y legal, que, hasta los años 50, no fue alterada con la reincorporación de las Fuerzas Armadas a tareas de orden interno. La idea de amenaza mutó en los años 60 con la ampliación de los grupos populares movilizados, el reto al derecho de propiedad privada y el triunfo marxista en la elección presidencial en 1970, determinando el ocaso de tales dispositivos y la demanda, antisocialista, por su militarización.

Palabras clave: Subversión, Coerción, Violencia, Estado.

Subversion, Coercion and Consensus: State Violence in 20th Century Chile

\begin{abstract}
This paper analyzes State repression in Chile between 1925 and the Pinochet coup of 1973. Its thesis holds that these practices emanated from political matters left unresolved by the 1925 Constitution and the political agreements of 1932, regarding the role of the State, the scope and nature of social rights, and the political
\end{abstract}


inclusion of Marxist parties. In other words, there was a lack of consensus around a common national agenda. Because systemic threats were of a peculiar, legally institutionalized nature, coercive measures were left to the police, keeping the armed forces away from domestic issues at least until the 1950s. This situation mutated in the 1960s, when the growth of popular mobilization, the challenge to property rights, and the Marxist victory in the 1970 presidential election rendered pre-existing methods ineffective, driving right-wing forces to demand anti-socialist military intervention.

Keywords: Subversion, Coercion, Violence, State.

La arraigada noción en Chile de haber constituido una excepcionalidad en el continente, un país políticamente estable, ajeno al militarismo y al populismo, capaz de resolver de forma institucionalizada sus conflictos, incidió de manera determinante en la apreciación respecto de la violencia estatal antes del golpe de 1973 como casi inexistente. Los énfasis estuvieron puestos en los avances sociales, en la conformación de un sistema político que albergaba a todo el espectro ideológico, incluyendo una izquierda marxista (partidos Comunista y Socialista) y una derecha conservadora y liberal, aún en medio de la Guerra Fría, y haber elegido democráticamente a un marxista como Presidente de la República. Esta mirada se reafirmó con la violencia dictatorial, los golpes mortales que le propinó a la militancia izquierdista y el terror sobre la sociedad en su conjunto, todo lo cual habría marcado un quiebre respecto de la etapa anterior (Álvarez, 2003; Pinto, 2006; Moulian, 1982).

Hace unos años, Brian Loveman y Elizabeth Lira comenzaron a estudiar las expresiones de violencia estatal en la historia del país, sosteniendo que existía una gran amnesia social, que calificaron como "las cenizas del olvido". Su tesis es que el Estado chileno estuvo reprimiendo al movimiento social desde sus orígenes, pero cada uno de esos episodios fueron excluidos de la historia mediante "olvidos deliberados", promovidos por la clase política, la cual, tras las masacres, decretaba la amnistía para los responsables. Esta lectura fue continuada con el estudio del papel del Poder Judicial en ese proceso, y la identificación de las leyes de seguridad interior del Estado (Loveman y Lira, 1999; 2000; 2013; Loveman, 2016). Esta línea ha sido complementada por quienes se han focalizado en algunos episodios específicos, como la Ley de Defensa de la Democracia que excluyó a los comunistas del sistema político, o rastreado la influencia determinante del anticomunismo, el impacto de esa persecución sobre el sistema político, los militantes de ese partido y sus familias (Huneeus, 2009; Casals, 2016, Alfonso, 2016; Bohoslavsky, 2011)

Este artículo analiza los dispositivos de represión estatal en Chile entre 1918-1973, entre la aprobación de la Ley de Residencia que permitía expulsar extranjeros, calificados como subversivos, y el golpe cívico-militar de 1973, que derrocó el proyecto histórico de la izquierda chilena, personificado en la experiencia socialista de la Unidad Popular. No se trató del derrocamiento de un gobierno cualquiera, sino de la principal amenaza al orden liberal-capitalista: el proyecto que articuló el conflicto político del siglo XX. 
En los últimos años, la historiografía del Cono Sur americano ha estado escudriñando la represión en regímenes reconocidos como democráticos, en los cuales los congresos aprobaron normativas que cercenaban derechos ciudadanos y otorgaban a las fuerzas policiales o castrenses facultades represivas, que excedían su función social, lo cual erosionó el estado de derecho y construyó un enemigo interno, "normalizando" la aplicación de medidas de excepción (Franco, 2012; Iglesias, 2010; Kierszenbaum, 2013).

Nuestra hipótesis sostiene que la represión estatal en Chile se relacionó con un conflicto político que la Constitución de 1925, y los acuerdos de 1932, no resolvieron, sin arribarse a reales consensos respecto al proyecto país, esto es, el papel del Estado, el carácter, amplitud y profundidad de los derechos sociales y la incorporación política de los partidos marxistas. Ello generó la idea de subversión. Los dispositivos represivos respondieron a un tipo de amenaza particular, legal-institucionalizada. Por ello, la coerción fue policial, de inteligencia y legal, y hasta los años cincuenta no fue alterada con la reincorporación de las Fuerzas Armadas a tareas de orden interno. La idea de amenaza mutó en los sesenta con la ampliación de los grupos populares movilizados, el reto al derecho de propiedad privada y el triunfo marxista en la elección presidencial en 1970, determinando el ocaso de tales dispositivos y la demanda de los grupos antisocialistas, por su militarización.

Los conceptos que articulan la hipótesis se enmarcan en la noción de seguridad interior del Estado, esto es, la conservación de la forma de Estado frente a conmociones internas que pudiesen alterar el orden existente y que implican una limitación de los derechos fundamentales, para asegurar una denominada "normalidad o tranquilidad social", un "estado de necesidad", que legitima estados de excepción constitucional (Frühling, 1982; Jiménez, 2010; Agamben, 2003). En el siglo XX ello se relacionó con el comunismo, lo cual favoreció una interpretación subversiva de gran parte de los problemas sociales, provocando, a veces, una militarización o una policialización de la seguridad. Entendemos por subversión aquellas corrientes ideológicas y movimientos populares, cuyo horizonte era la construcción de un orden distinto al liberal-capitalista que, de modo general, aspiraba al socialismo, calificados como comunistas, aunque no necesariamente lo eran, pero dentro de los cuales el Partido Comunista era percibido como el más peligroso. El "comunismo" subsumió, discursivamente, todas las amenazas. Entendemos por consenso, los acuerdos políticos básicos establecidos entre los actores en disputa, relativos al carácter del Estado, los derechos, las libertades públicas y la amplitud ideológica del sistema político. Por coerción, los dispositivos estatales, de naturaleza legal y policial, dirigidos a impedir transformaciones de fondo.

Este trabajo se apoyó en fuentes de archivos estatales, especialmente ministeriales y parlamentarias, prensa político-partidista, como revistas institucionales de la policía y del ejército. No ha sido posible acceder a archivos internos de esas instituciones, cerrados al público. 


\section{No matarás: el conflicto político entre 1918-1938}

El debate nacional acerca de la represión estatal comenzó con la aparición del movimiento obrero, en los inicios del siglo XX, cuyo desafío anticapitalista y de movilización desató numerosas masacres, ejecutadas por las Fuerzas Armadas. Considerando que el orden oligárquico excluía a todos los grupos ajenos a las elites, no existían canales institucionales para resolver los conflictos, y se apelaba a la fuerza militar cuando las paralizaciones obreras alcanzaban ribetes inaceptables. La matanza en la Escuela Santa María de Iquique, en el norte salitrero en 1907, representó un punto de quiebre, pues los militares dispararon contra una población indefensa de niños, mujeres y obreros, lo que generó un profundo impacto (Fernández Darraz, 2003; Devés, 1987). Entonces se abrió el debate al interior de la oligarquía respecto a la urgencia de una solución civilizada, materializada en leyes sociales y laborales, y en la no repetición de la matanza. Sin embargo, la crisis de la primera post guerra sorprendió al país sin que esta legislación hubiera sido aprobada, a diferencia de Argentina, donde sí se aprobaron leyes laborales desde fines del siglo XIX (Suriano, 1989).

Es importante resaltar esta conexión entre reforma social y represión estatal. En primer lugar, porque ha existido un amplio consenso historiográfico respecto a que todos estaban de acuerdo en legislar sobre cuestiones socio-laborales, casi como sinónimo de acuerdo programático (Yáñez, 2003); y, en segundo lugar, porque ello implicaba apartar a las Fuerzas Armadas de las tareas de orden interno. En realidad, tal consenso solo se refería a la necesidad de legislar, pero no al contenido de esas reformas, es decir, la naturaleza de los sindicatos, la existencia o no de federaciones, participación de anarquistas y comunistas, Estado intervencionista, etc. Los cambios que sobrevendrían alterarían el mundo de jerarquías, deferencias y de exclusión que era el oligárquico, como el carácter del Estado; ese era el meollo del conflicto. Por eso, la necesidad de buscar otros dispositivos represivos se ligaba al contenido de la reforma y al tipo de amenaza. En segundo lugar, si bien la oligarquía no desechó del todo la violencia castrense, ésta dejó de representar una solución, porque desde 1918 no provocó el repliegue obrero (Valdivia, 2017).

Esta imposibilidad de subordinación alteró la percepción oligárquica respecto de las demandas populares, sus organizaciones y acentuó un anticomunismo de antigua data: católico-conservador y liberal, acentuado con la revolución bolchevique. Como en otros países americanos, la idea de subversión inundó su pensamiento y el de las Fuerzas Armadas (Patto, 2002; Casals, 2016; Lvovich, 2016). En efecto, estas últimas coincidían con las elites en el anticomunismo, aunque nacionalista, con raíces prusianas e influencias corporativas. No obstante, descle Santa María de Iquique, la oficialidad joven desarrolló una aguda crítica a la oligarquía, a la que responsabilizó de las huelgas y la aparición de agitadores y doctrinas anticapitalistas, siendo partidarios de leyes sociales, intervencionismo estatal, proteccionismo, industrialización y un sistema político presidencial (Varas, Agüero y Bustamante, 1980). La subversión debía ser detenida con reformas. Fueron estos factores los que empujaron la búsqueda de nuevos dispositivos. 
Pretendiendo detener la influencia de doctrinas anticapitalistas y, siguiendo el ejemplo argentino, el 12 de diciembre de 1918, a pocos días de una gran "marcha del hambre", se aprobó una Ley de Residencia contra los 'agitadores', como un recurso de aplicación inmediata para expulsar a los cabecillas no chilenos del territorio nacional. Como señalaba el Ministro del Interior "esta es una ley de defensa en contra de aquellos que vienen a predicar...la subversión; no a predicar la transformación de nuestras instituciones por los medios constitucionales y a través de los organismos legales establecidos, sino...el trastorno violento del régimen social y político... la estimo salvadora y necesaria”. ${ }^{1}$ La ley prohibió la entrada a los extranjeros que promovieran la alteración del orden social o político por medio de la violencia, como de aquellos que propagaran "doctrinas incompatibles con la unidad o individualidad de la nación; de los que provocan manifestaciones contrarias al orden establecido, y de los que se dedican a tráficos ilícitos que pugnan con las buenas costumbres o el orden público." ${ }^{2}$

La Ley de Residencia respondió al diagnóstico hecho por liberales, conservadores, radicales y las Fuerzas Armadas respecto a que las huelgas respondían a la politización del movimiento obrero y al debilitamiento de las tendencias mutualistas y gremialistas. No rechazaban la existencia de orgánicas laborales, siempre y cuando se atuvieran a la Constitución y las leyes, es decir, concordaran en el orden liberal y capitalista, debiendo evitarse "la facilidad con que se concede personalidad jurídica a ciertas instituciones y federaciones obreras. Conviene... restringir estos permisos" ${ }^{3}$ Tampoco se rechazaba del todo la huelga, pero solo "como un procedimiento extremísimo para la condición (sic) de mejoras determinadas; pero, la censuramos cuando la promueve una intención diversa”. ${ }^{4}$ Como en Argentina, se responsabilizó a los promotores, "los agitadores extranjeros que...vienen a explotar los salarios de los trabajadores nacionales", ${ }^{y}$ " "fomentan el odio de clases, estimulando las huelgas y le otorgan un sello exaltado". ${ }^{6}$ Esta evaluación derivaba de la distinción entre masa y agitadores, pues mientras la primera sería pacífica y bastarían las leyes sociales para subordinarla, los denominados agitadores buscaban la transformación radical del orden existente. Así lo explicitaba una revista del Ejército dirigida a los suboficiales: "Día a día cunden, en el elemento estudiantil y también obrero, las falsas teorías del comunismo, símbolo si pudiéramos decir del desorden y la anarquía, difundidas en nuestro país por unos cuantos elementos sin patria, hombres audaces, y desposeídos de todo sentimiento patriótico". Esta interpretación no era privativa de Chile, sino compartida por otras clases dirigentes de la zona, como la argentina y la

1 Biblioteca Nacional (en adelante BN), Boletín de Sesiones de la Cámara de Diputados (en adelante BSCD), 26 de noviembre de 1918, p.703.

2 Biblioteca del Congreso Nacional (en adelante BCN) Ley № 3446 de Residencia, 12 de diciembre de 1918.

3 Archivo Nacional (en adelante AN) Ministerio de Guerra (MG), vol. 4520, auditor a interior, 7 de enero de1922, comunicaciones 1916-1924

4 BN (4 de agosto de 1920), El Diario llustrado, p. 3.

5 lbid.

6 BN, (5 diciembre de 1919), El Mercurio. Entre las FFAA, había algunas percepciones que, si bien los subversivos eran los dirigentes, la masa lo toleraba. (15 de junio de 1921), La Bandera, núm.3, pp. 54 y ss

7 BN, (15 de diciembre de 1922), La Bandera, Año II, núm. 12, pp. 371-372. 
brasileña, convencidas que la amenaza al orden social provenía de la acción de cientos de agitadores dispersos por el mundo (Constanzo, 2009; Lvovich, 2016). Por eso, la Ley de Residencia se dirigió a los cabecillas. Con todo, resultó ineficiente, considerando el carácter nacional del movimiento obrero chileno y la presencia exigua de extranjeros.

Fue este fracaso y la imposibilidad de solucionar un conflicto político que se agudizó bajo la presidencia de Arturo Alessandri (1920-1924), lo que desató los golpes militares de 1924 y 1925, y la redefinición estatal, condensada en la Constitución de 1925. Esta dio al Estado facultades económicas y sociales, garantizó los derechos sociales y las libertades civiles, satisfaciendo las demandas de capas medias y obreras y posibilitando la democratización. La nueva institucionalidad, sin embargo, también redefinió los aparatos represivos del Estado, los cuales deberían neutralizar a quienes resistieran política e ideológicamente el nuevo orden, pero apartando a las Fuerzas Armadas de las tareas de orden interno, salvo en lo penal. A diferencia del caso argentino, que en la primera década del siglo usó preferentemente legislación de excepción (Franco, 2019), en Chile se usaron dispositivos policiales, de inteligencia y también leyes de excepción. La oficialidad joven, liderada por el coronel Carlos Ibáñez, unificó las policías existentes, fiscales y municipales, con los carabineros -una unidad el ejército-, creando en 1927 el Cuerpo de Carabineros, una policía semi-militarizada, dependiente del Ministerio del Interior y con presencia a lo largo del país, encargada del orden público y social. La incorporación de una unidad militar y la influencia castrense en su creación incidieron en el tipo de medios que utilizaría para imponer el orden, muy represivos: lanzas, rifles, carros antimotines (Maldonado, 1990). Asimismo, se creó el Servicio de Investigaciones y Pasaporte, dirigido a recabar información de los grupos contestatarios, dirigentes obreros, militantes comunistas y ácratas y toda disidencia activa (Plaza, 2018), aunque nunca adquirió el carácter de los Departamentos de Orden Político y Social (DOPS) brasileños. Un tercer instrumento fue el Servicio de Identificación que impuso la cédula de identidad para toda la población, lo que coincidía con tendencias europeas y del Cono Sur americano (About y Denis, 2011; Fessler, 2015). La cédula de identidad consignó nombre y nacionalidad de la persona, edad, estado civil, profesión u oficio, estado de alfabetización y una fotografía "de frente con el número del prontuario perforado en la misma, la impresión dígito del pulgar derecho y de otro dedo, si este no existiere y la clasificación dactiloscópica”. ${ }^{8}$ El decreto-ley dispuso la identificación, personal y obligatoria, dependiente de la Dirección General de Policías, el que abriría prontuarios y recabaría antecedentes policiales y judiciales (García Ferrari y Galeano, 2015).

Un cuarto dispositivo, coincidiendo con la experiencia brasileña (D’Araujo, 2010), ${ }^{9}$ fue la legislación dirigida a sancionar las tendencias políticas de orientación anticapitalista, tipificándolas como delito: decreto-ley de Seguridad Interior del Estado, emitido por el Ministerio de Justicia el 27 de septiembre de 1924, a 
días del golpe militar que impuso las primeras ocho leyes sociales en Chile. La norma establecía que todos los delitos cometidos por militares y civiles contra la seguridad interior caían bajo jurisdicción militar en cuanto a su "secuela y juzgamiento, y al Código Penal en cuanto a la sanción que les corresponda”. ${ }^{10} \mathrm{Se}$ entendería por delito contra la seguridad del Estado aquellos que se alzaran en armas contra el gobierno constituido para provocar una guerra civil, cambiar la Constitución o su forma de gobierno; para impedir la promulgación o ejecución de las leyes, la realización de elecciones y que coartaran el ejercicio a cualquiera de los poderes constitucionales, so pena de reclusión, confinamiento y extrañamiento menor. Este decreto-ley de seguridad interior satisfacía la demanda de conservadores, liberales y radicales de coartar ciertas garantías constitucionales, como los derechos de reunión y de expresión, profusamente usados por el movimiento obrero, porque creían que a través de la institucionalidad se expandía el "comunismo anárquico", "amparado por nuestra libérrima (sic) Constitución"." Los militares coincidían en este diagnóstico, pues se carecía de herramientas legales para impedir los comicios y la publicación de prensa comunista y anarquista. En ese sentido, para mediados de los años veinte, se logró un consenso dentro de los partidos oligárquicos y los militares respecto de esta normativa de excepción, que tipificó como delito las apuestas políticas antiliberales y anticapitalistas.

Ni la Constitución ni los dispositivos represivos resolvieron la crisis, por las controversias que causaban, lo cual derivó en la dictadura del coronel Carlos Ibáñez (1927-1931), quien impuso el intervencionismo estatal y los derechos sociales y laborales, en contra de quienes se resistían: el empresariado, que seguía defendiendo un orden regido por el mercado y un Estado que solo creara las condiciones para su expansión, intentando suspender o modificar las leyes sociales, especialmente las de previsión y de accidentes del trabajo; también contra el movimiento obrero de tendencias revolucionarias, reprimiendo a sus cabecillas y obligando al conjunto de los trabajadores a aceptar una legislación que reconocía derechos a un segmento limitado de ellos e imponía un papel tutelar al Estado. Mientras los comunistas fueron perseguidos, amplios sectores del anarcosindicalismo y del mutualismo adhirieron a la legislación social (Rojas, 1993). Tras la caída de Ibáñez, se produjo una alianza entre la oficialidad ibañista y nacientes sectores socialistas, no comunistas, en la "República Socialista” (1932), que acentuó el intervencionismo económico y social del Estado, pero despertó temores respecto del poder militar (Valdivia, 2017).

A pesar del anticomunismo doctrinario de las Fuerzas Armadas, ${ }^{12}$ a fines de 1932, todos los partidos acordaron apartarlas de la política y aceptaron la Constitución de 1925, es decir, la institucionalidad surgida de los catorce años previos de lucha. Ese fue el consenso básico, no así su sentido y alcance. En efecto, tras superar sus conflictos internos, la izquierda (comunistas y socialistas ${ }^{13}$ ) se unió políticamente

10 BCN, Decreto-Ley No.15 sobre Delitos contra la Seguridad Interior del Estado.

11 BN, (2 de marzo de 1921), El Diario Ilustrado, p.3 El énfasis es nuestro.

12 “La patria y los errores del comunismo”, AN MG, vol. 6231, 1936.

13 EI PS nació en abril de 1933 y reunió a sectores marxistas, anarquistas, trostkistas, corporativistas, en torno a un programa marxista, antisovietista, pero muy influido por el latinoamericanismo. 
y bajo una federación sindical -la Confederación de Trabajadores de Chile, CTCH-, optó por institucionalizarse. Junto al Partido Radical esperaban usar toda la potencialidad económica y social del Estado en favor del bienestar popular y no solo de los trabajadores sindicalizados, que eran la minoría, mejorando su consumo, salud y habitación. La izquierda y el movimiento obrero lucharían porque las leyes sociales llegaran hasta sectores no incluidos (obreros de pequeñas industrias) o expresamente excluidos (de empresas privadas que atendían servicios: tranviarios, ferroviarios, empleados fiscales, municipales, etc.), lo cual implicaba traspasar los límites del Código del Trabajo con huelgas calificadas de "ilegales". Igualmente, significaba, reforzar la participación político-electoral de comunistas y socialistas. Las derechas (partidos, empresarios, prensa) buscaban limitar el reconocimiento de derechos solo a los ya establecidos (trabajadores mineros y portuarios industriales no), impidiendo la consolidación del poder obrero, esto es, limitando el número y tipo de organización sindical, su prensa y su uso de la institucionalidad. Especialmente, se buscaba excluir a los campesinos de los derechos de sindicalización, algo reconocido en el Código, pero suspendido por presión de los terratenientes, quienes lograron conservar el latifundio y el control político del campesinado, manteniendo una sobrerrepresentación parlamentaria que le permitía bloquear la expansión de las leyes sociales y la injerencia económica del Estado (Gómez, 2004; Valdivia, 2020; Valdivia y Pinto, 2020). Esta ambigüedad del consenso explica la persistencia de los dispositivos represivos, a pesar del reconocimiento amplio de la institucionalidad. Dichos dispositivos serían usados para coartar el potencial democratizador de la Constitución, que garantizaba en su artículo 10, los derechos sociales para el conjunto social.

En su segundo gobierno, Alessandri (1932-1938) pretendía afirmar la institucionalidad de la Constitución de 1925, reconociendo el nuevo Estado y el restrictivo Código del Trabajo, impidiendo rebrotes militaristas y la expansión de la izquierda marxista, vista como la principal amenaza. Por ello, consolidó los dispositivos estatales de represión generados en la etapa anterior: reforzó la subordinación de Carabineros al Ejecutivo, reorganizó el Servicio de Investigaciones y de Identificación, como aparato de inteligencia a su servicio (Plaza, 2018), y recogió las normas de excepción, no solo el decreto-ley de 1924, sino también el proyecto conservador de 1931, que buscaba castigar no solo las acciones perpetradas, sino penalizar las doctrinas utópicas y la expresión de opiniones consideradas atentatorias a la estabilidad institucional, y que consideró la huelga como delito político. Asimismo, el decreto-ley 50, de agosto de 1932, definió delitos contra los "enemigos de la República", esto es "toda persona que propague o fomente, de palabra o por escrito, doctrinas que tiendan a destruir por medio de la violencia el orden social o la organización política del Estado". ${ }^{14}$ Alessandri legitimó el derecho de los gobiernos a dictar leyes represivas en resguardo y defensa de su integridad política y social, armando al "Ejecutivo y al país de todos los elementos de defensa contra el más esforzado y peligroso de sus enemigos, cual es el comunismo integral, que lucha denodadamente por derribar y destruir la República y el régimen democrático establecido en nuestra Constitución para substituirlo por la dictadura del 
proletariado y para abolir la propiedad privada”. 15 Durante la discusión parlamentaria, el diputado conservador Arturo Gardeweg afirmó: "La verdadera trascendencia del proyecto es la de legitimar disposiciones en vigencia", ${ }^{16}$ es decir, los decretos del período 1924-1932. Parlamentarios de izquierda y algunos radicales votaron en contra de una ley que restringía las libertades "so pretexto de velar por la seguridad interior del Estado, porque si tal cosa estuviera autorizada por la Constitución política, las libertades que ella asegura y garantiza a los ciudadanos serían ilusorias". ${ }^{17}$ La lucha contra la subversión sería policial y con leyes de excepción, que coartaban derechos garantizados por la Constitución.

La renuncia a recurrir a las Fuerzas Armadas se debió, en el caso de la derecha, a las dictaduras de 1932, que ampliaron las atribuciones económicas estatales, incluyendo la facultad de requisar la propiedad privada (DL 520). La derecha optó entonces por combatir a sus enemigos dentro de la institucionalidad, donde se enquistaron, y no mediante la militarización, salvo en situaciones vistas como muy peligrosas (Valdivia, 2019). La izquierda decidió concentrarse en la organización, conciencia y expansión del movimiento obrero, apropiándose del potencial democratizador contenido en la Constitución. A diferencia de Brasil, los comunistas nunca tuvieron presencia en las filas militares, y los socialistas, que sí la tenían, renunciaron a ese recurso y su principal líder -el coronel (retirado) Marmaduque Grove-actuó como civil, sin politizar a sus ex camaradas. Los radicales rompieron con sus contactos militares porque se transformaron en el eje del Frente Popular, imponiendo a sus militantes como figuras presidenciables; afianzaron su estatismo económico-social, aunque en su interior existían sectores muy anticomunistas. Es decir, a pesar de sus deficiencias, la institucionalidad de 1925 fue legitimada por todo el espectro partidario, por lo cual el sistema no estalló "en mil esquirlas", como en Argentina, haciendo posible el peronismo (Zanatta, 2011), ni se estableció una convivencia cívico-militar, como en el Brasil de Vargas. Los militares fueron apartados del conflicto y eso señala una gran distinción en el tipo de represión estatal. El caso chileno tiene más puntos de contacto con el uruguayo, por el uso en ese país de las Medidas Prontas de Seguridad, equivalentes a las de seguridad interior, pero en Chile el sistema integró un sector doctrinariamente marxista, cuyo horizonte era el socialismo. De allí la disputa por una institucionalidad más democratizadora o más autoritaria. En ese intersticio, se consolidaron los dispositivos represivos.

La apuesta institucional de la izquierda fue coronada por la conformación del Frente Popular (comunistas, radicales y socialistas) en 1936 y el triunfo en las elecciones presidenciales de 1938. Un nuevo ciclo comenzó con el ascenso de la centro-izquierda al gobierno, pues su control le entregó una amplia gama de facultades y la capacidad de incidir determinantemente en la agenda política, no yendo a remolque, como ocurrió en otras experiencias que incluyeron partidos comunistas en el sistema político, pero sin fuerza alternativa real. En Chile, socialistas y comunistas fueron claves en el proceso político vivido por el país desde entonces. Esa era la principal amenaza.

15 "Oficio de S.E...", op. cit., p.388.

16 BCN BSCD, 14 diciembre de 1936, p. 714.

17 BCN BSCD, 14 diciembre de 1936, p. 719. 


\section{Un conflicto interno-externo: la Segunda Guerra Mundial y la Guerra Fría, 1938-1958}

Mirada desde la represión estatal, la segunda fase cubriría los siguientes veinte años, coincidiendo con su calificación como Estado de compromiso, considerado el estilo político de negociación y acuerdo, dentro de un sistema de partidos polarizado ideológicamente -socialismo vs liberal-capitalismo-, mediado por el partido Radical, y en el cual el Estado asumió importantes funciones empresariales, como estimulador del desarrollo económico y social, garantizador de los derechos de los trabajadores, habiendo elecciones periódicas y competitivas (Moulian, 1982 y 2006). En 1938, por primera vez en la historia del país una coalición no oligárquica, de centro-izquierda, ganó el ejecutivo y reforzó sus atribuciones en favor del mundo popular y del desarrollo industrial y urbano del país; el mundo obrero logró representación política, sus líderes ocuparon posiciones en el aparato estatal y determinaron la agenda política nacional, en consonancia con el auge del populismo en la región. Aunque el Frente Popular como tal solo duró hasta 1941, hasta comienzos de los años cincuenta, se mantuvieron alianzas entre radicales, socialistas y, por momentos, los comunistas.

Sin embargo, esta etapa también se caracterizó por la militarización del conflicto, esto es, la reincorporación de las Fuerzas Armadas a tareas de orden interno, contradiciendo el sentido de la reformulación estatal de los años veinte, que buscaba apartar a esas instituciones de tales labores, decretando estados de excepción constitucional. La militarización política se refiere a la intervención de los militares en el debate y la acción política,irrumpiendo en ámbitos propiamente civiles, como la apropiación por éstos de principios y lógicas castrenses (Portales, 1982). Esta militarización era distinta de la argentina, y también de la brasileña, pues el control y liderazgo político siguió radicando en los civiles, sin tutela militar ni autonomización. Estos estados de excepción daban cuenta de los límites de los consensos políticos, pues se acudía a ellos cuando el conflicto no encontraba vías políticas de solución.

Nuestro marco temporal (1938-1958) se justifica en la naturaleza del conflicto político en Chile, definido hasta fines de los años cincuenta por la cuestión obrera, visto, junto al Partido Comunista, como la principal amenaza al orden capitalista existente, considerando su persistencia institucionalizadora, la fuerza que ella le ofrecía y su impacto en el Estado. Por ello, los cuatro dispositivos represivos se mantuvieron vigentes.

La Segunda Guerra Mundial, sin embargo, reposicionó a las Fuerzas Armadas en la política de los países latinoamericanos, cuando Estados Unidos organizó una estructura defensiva hemisférica y se sentaron los pilares para una cooperación estratégica interamericana. En la reunión en La Habana en 1940 se aprobó una "Declaración de cooperación y asistencia recíproca para la defensa de las Américas" ante un ataque a algún país americano de parte de un Estado extracontinental, considerándolo una agresión al continente, pudiendo adoptarse medidas de cooperación defensiva, coordinación policial y judicial, para enfrentar al Eje y la actuación de posibles “Quintas Columnas” (Fermandois, 2005). 
Esta cooperación significó un reordenamiento en todos los ámbitos, desde lo económico-financiero y la defensa hemisférica hasta la represión de la subversión interna, entonces asociada a los nacionales del Eje, mediante acciones para impedir sabotajes a las unidades productivas y de transporte, controlando el movimiento de los trabajadores. Tras el ingreso formal de Estados Unidos en la guerra, las fuerzas armadas chilenas aseguraron las fronteras, especialmente las costas, donde se suponía podrían ocurrir ataques y recibieron armas, adiestramiento de personal militar, ayuda civil y créditos (Valdivia, 2020; Bawden, 2016). Ello se insertó dentro del "Plan general de defensa del territorio", es decir, el "frente interior, llamándose así a todo el espacio del territorio que queda fuera de la zona donde se desarrollan las acciones directas de la guerra (teatro de operaciones)... las grandes ciudades, los centros industriales, las propias fronteras terrestres y marítimas, las vías férreas y aéreas, los caminos". ${ }^{18}$

Estos cambios se consolidaron con la sanción de tres leyes: la Ley 7144 (1941) creó el "Consejo Superior de Defensa Nacional" para "asesorar al gobierno en el estudio y resolución de los problemas que se refieren a la defensa nacional relacionadas con la seguridad exterior del país", en el que participarían los ministros de Defensa, Hacienda y Relaciones Exteriores, los Comandantes en Jefe de las tres ramas de las Fuerzas Armadas, los Jefes de los Estados Mayores, los Subsecretarios de Guerra, Marina y Aviación. Esta ley devolvió formalmente a los comandantes en jefe participación en la toma de decisiones y dio un peso mayor a los militares dentro del Consejo. Por su parte, la Ley 7401 sobre "Seguridad Exterior del Estado", aprobada el 4 de enero de 1943, antes de la ruptura con el Eje, declaró delito todo acto que favoreciera a países en guerra con algún Estado americano o sus aliados, enviara información al exterior, publicara movimientos de barcos o cualquier acción contra instalaciones de servicio público o industrias destinadas a la defensa.

La Ley 7200, de 21 de julio de 1942, fue la más importante, dictada a sugerencia de Estados Unidos. Otorgó facultades extraordinarias al Presidente Juan Antonio Ríos para "Dictar disposiciones de carácter administrativo, económico y financiero", y en su artículo 23 lo autorizó, previo informe del Consejo Superior de la Defensa Nacional, para declarar "Zona de Emergencia" partes del territorio nacional en caso de peligro de invasión o ataque exterior, pero también ante sabotajes contra la seguridad nacional. En esos casos, se podría afectar el no 13, del artículo 44 de la Constitución (sobre derechos civiles) y el no 17 del artículo 72 (estado de asamblea y de sitio) contra las personas u organizaciones que realizaran ese tipo de acciones. Esta ley fue complementada con el DFL no 34/2245, de 1 de noviembre de 1942, que definió sabotaje como "toda acción encaminada a destruir o perjudicar armamentos, municiones, elementos bélicos o instalaciones de cualquier clase relacionadas con algún servicio público, empresas o industrias útiles a la Defensa, aprovisionamiento o economía del país, o a los medios de locomoción o comunicación que tiendan a perturbar la defensa nacional”. Por el artículo 2o.se

18 Mayor Ramón Salinas Figueroa "El Plan general de defensa del territorio", Memorial del Ejército de Chile, nov.-dic., 1941, p. 879. 
estableció que la autoridad militar y administrativa de la Zona de Emergencia era el Jefe Militar o Naval de la División o Apostadero respectivo y subordinaba a todas las autoridades civiles y policiales de la Zona (Valdivia, 2020).

Estas tres leyes alteraron las relaciones cívico-militares, pues entregaron a los militares tareas de orden interno, integrando a sus altos mandos a las discusiones y decisiones políticas, entregando autoridad a los oficiales en las Zonas de Emergencia, en todo el territorio nacional, en coyunturas que se definieran como tales. El hecho de que se haya definido el sabotaje en relación, no solo a los elementos bélicos, sino a servicios de utilidad pública e industrias, abrió un espacio para aplicar dicha norma al movimiento sindical, toda vez que la locomoción colectiva y numerosas empresas urbanas e industrias, eran un servicio de utilidad pública, que en caso de huelga no abastecía a la población. Por su parte, el artículo 3 del DFL 34/2245, dotó a las Fuerzas Armadas de libertad de iniciativa para restringir derechos, coartar la libertad de movimiento, definir lo que se entendería por propaganda antipatriótica, vigilar a las personas o restringir el porte de armas, ampliando una capacidad que ya tenía Investigaciones y Carabineros.

A mediados de enero de 1943, días antes de la ruptura con el Eje, el gobierno declaró en Zona de Emergencia diversos lugares del territorio nacional y autorizó a los "comandantes en jefe de apostaderos y comandantes de Regiones Militares en esas zonas establecidas dentro de su jurisdicción, para imponer todas o algunas de las restricciones comprendidas en el no 13 del Art.44 de la Constitución Política del Estado y en la extensión que ellas fueran necesarias". ${ }^{19}$ Las regiones escogidas eran las económicamente estratégicas y las costas, susceptibles teóricamente de un ataque de las potencias del Eje, ya que el cuerpo de Carabineros "no cuenta con el personal suficiente para atender a la adecuada vigilancia de esas zonas". ${ }^{20}$

Las "Zonas de Emergencia”, pensadas para una situación de ataque externo, fueron usadas desde un comienzo contra el movimiento obrero, pues permitían coartar libertades públicas, sin trámite judicial. Apenas aprobada la Ley, el diputado comunista César Godoy denunció los atropellos a las libertades en el puerto cuprífero de Chañaral: "se han cometido violaciones, transgresiones y abusos a las leyes, por invasión, por parte del Jefe de Plaza de facultades que corresponden al orden civil... desconociendo las leyes que garantizan los derechos de los ciudadanos y el uso de las libertades públicas". ${ }^{21}$ Regiones donde hubo huelgas de otros yacimientos controlados por compañías estadounidenses, como Potrerillos y Chuquicamata en 1945, fueron declaradas Zonas de Emergencia "Con el objeto de adoptar las medidas adecuadas al mantenimiento del orden y la seguridad", 22 lo mismo ocurrió en la zona carbonífera en enero de 1946: "para vigilar el desarrollo de las actividades huelguísticas y controlar el orden. En estos momentos

19 “Ministerio del Interior, 15 enero de 1943, AN MI, Oficios Confidenciales, vol.11166, 1943.

20 AN “Dirección General de Carabineros a Ministro de Defensa Nacional”, 17 agosto de 1942, FMI, Oficios Confidenciales, vol. 10818, 1942.

21 BCN, BSCD, 1 de diciembre de 1943, p.744.

22 BN, (19 de octubre de 1945). El Siglo, Santiago, p.1. 
viaja con destino a Coronel un tren especial con tropas del ejército". ${ }^{23}$ Santiago, el norte salitrero, Concepción y Lota estuvieron en manos de las fuerzas militares.

Estos numerosos estados de excepción se relacionaron con un nuevo ciclo de huelgas, controladas hasta 1945 por la coalición de centro-izquierda y el apoyo a los Aliados en la guerra, consenso que se resquebrajó con la Guerra Fría y el proceso de industrialización y urbanización. Respecto de lo primero, los comunistas radicalizaron sus demandas laborales, incidiendo en la oleada de huelgas, a la vez que la emergencia de la URSS acicateó el anticomunismo de sectores del Partido Socialista, provocando la ruptura de la izquierda. En relación a lo segundo, desde 1938 se había estado produciendo un significativo crecimiento industrial y de urbanización, incrementando la masa laboral, aunque una mayoría de ella no estaba contemplada en el Código del Trabajo, por lo que sus paralizaciones eran declaradas ilegales y sus demandas eran resistidas por los patrones y las derechas, lo que dejaba al Estado como árbitro. La grave situación económica que sobrevino después de la guerra, con altos niveles de inflación y serias restricciones crediticias tensó el conflicto (Cavarozzi, 2017), favoreciendo su militarización. Cuando las negociaciones entre patrones y obreros llegaban a un punto muerto o se declaraban huelgas de solidaridad, como ocurrió entre 1945 y 1947, los gobiernos usaron las Zonas de Emergencia para controlar al movimiento obrero. Así, mientras en Uruguay las "Medidas Prontas de Seguridad" fueron utilizadas reiteradamente para controlar a los trabajadores, en Chile ese lugar lo ocuparon las Zonas de Emergencia. Esta militarización del conflicto, a diferencia del caso argentino, estaba bajo liderazgo civil, de donde emanaban las órdenes, y, salvo excepciones, ella no conllevó represión por parte de los uniformados, sino control de la libertad de expresión y prensa, de circulación y de actividad política de los trabajadores. Junto a la militarización, el gobierno aplicaba la Ley de Seguridad Interior del Estado de 1937 a los dirigentes sindicales, quienes eran apresados; no obstante, la intervención de parlamentarios o jefes de partidos ante el Ejecutivo, abría nuevos canales de solución y los presos eran liberados.

A nuestro entender, la tesis de las "amnesias" deliberadas, propuesta por Lira y Loveman, debe ser repensada. El repliegue del gobierno obedecía a la doble necesidad de asegurar la producción, pero también de mantener el compromiso con los trabajadores en un marco institucional tan restringido, pues aunque la CTCH no tenía personalidad jurídica, los gobiernos la reconocieron como interlocutora válida porque representaba al movimiento obrero y la izquierda, parte de la alianza de gobierno. Por eso, el período 1938-1958 es distinto del anterior, en tanto los factores políticos tenían un papel crucial y bajo liderazgo civil. El uso de las Zonas de Emergencia alcanzó amplia legitimidad entre los dirigentes políticos de centro y derecha, porque permitían resolver cuellos de botella y no implicaban represión física, era un cese momentáneo de hostilidades, que facilitaba retomar el diálogo y controlar el orden interno. Sin embargo, ello fue sedimentando un anticomunismo real, existente no solo en las derechas y las Fuerzas Armadas, sino también entre socialistas y radicales. 
La tesis del Estado de compromiso sostiene la existencia de una derecha capitalista-liberal, y una izquierda marxista dentro del sistema político, como si hubiesen podido convivir armónicamente (Moulian, 1982). Ella, sin embargo, no considera los variados anticomunismos, de larga data, presentes en amplios sectores políticos: un anticomunismo doctrinario de derecha con una gran capacidad de movilización social, especialmente ligado a sectores altos y medios; y un anticomunismo más coyuntural, socialista, de raíz trostkista o ácrata.

El anticomunismo más importante en Chile fue el de derecha, conservador-católico y el liberal, que jamás aceptó el tipo de Estado surgido de la Constitución de 1925 y la incorporación del Partido Comunista al sistema político, intentando excluirlo, presentando numerosos proyectos de ley $(1940,1941)$ dirigidos a declararlo ilegal, de modo de expulsar a sus parlamentarios, impedir el accionar de sus dirigentes obreros y erradicarlos del aparato estatal, en los momentos en que ocuparon cargos, porque "Entre nosotros, legalmente, no puede existir el Partido Comunista, ni aspirar a cargos representativos". ${ }^{24}$ Conservadores y liberales exigían la aplicación de las leyes de seguridad interior que declaraban a ese partido asociación ilícita. Las alianzas de centro-izquierda rechazaron sistemáticamente este intento. En ese sentido,la aplicación de las normas de excepción tenía un efecto momentáneo, de detener las huelgas y apresar a los dirigentes obreros y comunistas, temporalmente, al aplicárseles las leyes de seguridad y decretar Zonas de Emergencia, pero no frenaba el avance socio-político del comunismo, la izquierda en general y el movimiento obrero. Tras la pacificación lograda con las Zonas de Emergencia, la política recuperaba su preeminencia.

Fueron estos procesos los que, finalmente, hicieron posible el dictado de una ley que excluyó a los comunistas del sistema político, la Ley de Defensa de la Democracia o Ley Maldita, en 1948, en el marco de la Guerra Fría (Huneeus, 2009), la que estuvo vigente diez años y prohibió "la existencia, organización, acción y propaganda, de palabra, por escrito o por cualquier otro medio del Partido Comunista y, en general, de cualquier asociación, entidad, partido, facción o movimiento que persiga la implantación en la república de un régimen opuesto a la democracia o que atente contra la soberanía del país". ${ }^{25}$ La militarización ocurrida y la presión estadounidense por una expulsión total de los comunistas de los sistemas políticos en Latinoamérica, determinaron la creación de un campo de prisioneros políticos en el puerto salitrero de Pisagua, en 1948, como parte de la Zona de Emergencia. Los obreros carboníferos y salitreros fueron acusados de promover una huelga revolucionaria, siendo apresados, junto a dirigentes políticos comunistas, embarcados hacia el puerto de Iquique en naves de la Armada y recluidos en el campo de Pisagua. Allí estuvieron bajo la custodia de las Fuerzas Armadas, aunque debían reportarse diariamente a Carabineros. El "campo de Pisagua" se mantuvo abierto entre noviembre de 1947 y febrero de 1949, aunque siguió recibiendo presos hasta comienzos de los años cincuenta. (Valdivia, 2020). Los conservadores rechazaron las presiones por derogar la "Ley Maldita” y reincorporar a los comunistas, pues la

24 BN, (15 de febrero de 1940), El Diario llustrado, Santiago, p.3.

25 Santiago, Ministerio del Interior Ley de Defensa Permanente de la Democracia, 1948. 
exclusión se fundaba "en una legislación aprobada por el propio congreso... creemos que el bien de Chile radica en que este gobierno o cualquier otro legalmente constituido, tenga las armas legales necesarias para defender la organización democrática y jurídica de la república”. ${ }^{26}$

El campo de Pisagua provocó un impacto político muy grande, pues se contradecía con el historial "democrático" que se asociaba al país, suscitando el activo rechazo de comunistas, social-cristianos, que se separaron del partido Conservador, y algunos radicales y socialistas, quienes presionaron por la derogación, a través del 'Comité de solidaridad y defensa de las libertades públicas. ${ }^{27}$

Esta demanda fue un elemento central en la candidatura del ex dictador Carlos Ibáñez, quien ganó la elección presidencial de 1952 y gobernó hasta 1958. Durante su administración, el eje del conflicto siguió estando en la confrontación institucionalizada entre los trabajadores urbanos organizados -ahora en la Central Unitaria de Trabajadores, CUT-, sus referentes partidarios y los empresarios, con intermediación del Estado. Por ello, la idea de amenaza siguió radicando en el movimiento obrero y la izquierda marxista, de comunistas y socialistas. El tipo de represión utilizada se mantuvo dentro de los dispositivos existentes, sin que la nueva fase de Guerra Fría, bajo Einsenhower, tuviera un efecto muy visible todavía, aun cuando el alineamiento con Estados Unidos avanzó y reconfirmó la misión de las Fuerzas Armadas de mantener el orden interno de sus respectivos países: "Con respecto al rol de la defensa hemisférica, se espera que las Fuerzas Armadas de América Latina sean capaces de mantener la seguridad al interior de sus propios territorios, incluyendo la prevención de disturbios revolucionarios, operaciones clandestinas enemigas, defensa contra ataques y sublevaciones, protección de las fuentes de materiales estratégicos, protección de las vías de comunicación, seguridad local de las bases militares y suplementos militares" (Romano, 2012: 224). Se inició el entrenamiento y la asistencia en equipos. Las Fuerzas Armadas chilenas adhirieron a los lineamientos de Seguridad Nacional, en tanto ello permitiría su modernización e incorporación al mundo, sin que alterara su participación en tareas de orden interno, como lo reflejó su interpretación de las Zonas de Emergencia:

El estado Zona de Emergencia no significa establecer la jurisdicción militar de tiempo de guerra...las atribuciones del Jefe de la Zona de Emergencia son amplias, tanto en el orden administrativo como en la restricción de las libertades de expresión, y de circulación y en la limitación del derecho de propiedad. Entre sus facultades administrativas está la de dictar bandos, fijando normas a las que debe ceñirse la población civil. ${ }^{28}$

26 BCN, BSCD, 3 spte. de 1953, p. 2515.

27 BN, Santiago, Comité de Solidaridad y Defensa de las Libertades Públicas El Estado Policial o la Ley de Defensa de la Democracia, Santiago, 1951.

28 Mayor Carlos Prats, "Importancia estratégica, administrativa y logística de la división territorial del teatro de guerra y su relación con los códigos de la República", Memorial del Ejército de Chile, marzo-abril de 1953, p.36. 
A pesar de la interamericanización de la lucha anticomunista, Ibáñez y los sectores políticos que lo apoyaban, siguieron recurriendo a los dispositivos coercitivos vigentes, sin involucrar de otra forma a los militares, aunque se incrementó el dictado de Zonas de Emergencia (1955, 1956 y 1957), como también el número de efectivos militares y en 1957 hubo despliegue de tanques en la ciudad (Valdivia, 2020).

Esta persistencia de los resortes de represión estatal es importante porque durante los años cincuenta los frágiles consensos, de que hemos dado cuenta, comenzaron a fracturarse, en importante medida, por la grave crisis económica y la inflación, que deterioró mucho el consumo popular y los salarios, lo que hizo recrudecer las huelgas. La Central Única de Trabajadores, creada en febrero de 1953, adoptó una posición mucho más confrontacional con los patrones y el ejecutivo, impulsando numerosas paralizaciones, incluyendo un paro general a mediados de 1955. Esta crisis económico-social tuvo su correlato en el sistema político, que comenzó a rearticularse: el centro, representado por los radicales, perdió gran parte de su respaldo electoral, ganando fuerza el centro católico-reformista de la Democracia Cristiana, que comenzó a restar bases a la derecha. Ésta inició su modernización, con la aparición de una derecha tecnocrática, mucho más liberal, en términos económicos, y partidaria de frenar definitivamente el avance sindical y de la izquierda, con una apuesta autoritaria. La izquierda, contrariamente, consolidó su unidad -el Frente Revolucionario de Acción Popular (FRAP)-, pero optando por un camino propiamente izquierdista, rechazando la alianza subordinada con el centro y actualizando el horizonte socialista con transformaciones estructurales. En ese sentido, en la segunda administración ibañista los actores que entablaron el acuerdo de los años treinta, comenzaron a cambiar su fisonomía. Aun así, hasta 1958 nadie planteó modificar los dispositivos con que contaba el Estado para reprimir, salvo la presión por devolver al sistema partidario su pluralismo, reincorporando a los comunistas.

Un amplio acuerdo entre comunistas, socialistas, democratacristianos y algunos radicales, permitió derogar la "Ley Maldita” en 1958, pero Ibáñez insistió en reemplazarla por una nueva Ley de Seguridad Interior, que eliminó la proscripción del comunismo, pero integró el resto del articulado, que coartaba las libertades de reunión, expresión, de prensa, etc., incluyendo la tipificación de la huelga como delito. En ese sentido, para 1960 la legislación de excepción seguía apareciendo como una eficaz herramienta de combate a la subversión, junto a Carabineros, Investigaciones y el Servicio de Identificación.

\section{Hacia la militarización total}

Una tercera fase puede identificarse entre 1958-1973, en la cual cambió la percepción de amenaza y ello afectó los consensos sobre los tipos de dispositivos represivos existentes para enfrentarla. 
Los factores que incidieron fueron cuatro. En primer lugar, las transformaciones estructurales promovidas por el gobierno democratacristiano (1964-1970), como la reforma agraria y la organización de los pobres urbanos y rurales, bajo el programa de "promoción popular". Por ello, en segundo lugar, en los sesenta se produjeron transformaciones en el movimiento social, integrándose pobladores, campesinos y una nueva generación de universitarios, que presionaron por cambios en el derecho de propiedad, la democratización del poder y que fueron movilizados por democratacristianos, comunistas, socialistas y el MIR (Movimiento de Izquierda Revolucionaria). Un tercer elemento fue la aparición, ya formal, de derechas e izquierdas nuevas: derechas tecnocráticas, liberales extremas, otras corporativistas, nacionalistas, todas muy combativas, como el Movimiento Gremial de la Universidad Católica -franquista-, o el Movimiento Nacional Sindicalista, ante el declive de conservadores y liberales. La aprobación del voto secreto en 1958 puso fin al control terrateniente del voto campesino y el cohecho. En la izquierda se sintió el impacto cubano, actualizando la meta socialista y surgiendo movimientos partidarios de la lucha armada, aunque con capacidad bélica muy menor (MIR). Estos nuevos grupos alteraron los discursos, las prácticas políticas y favorecieron una alta movilización popular por el derecho de propiedad urbana y, especialmente, rural, desafiando al latifundio. En cuarto lugar, la Guerra Fría interamericana entró en una nueva fase con la revolución en Cuba, acentuándose la presión por incorporar a las Fuerzas Armadas a tareas de orden interno.

Como resultado, la amenaza dejó de remitir solo a los obreros, incluyendo un mundo popular más vasto y variado, que puso en jaque el derecho de propiedad privada, pivote del acuerdo constitucional de 1925. Aunque la reforma agraria de la DC no fue radical, dio un golpe mortal al orden señorial, provocando la movilización campesina en demanda de tierras a partir de 1968, al tiempo que la "Promoción popular" movilizó a las/os pobladores por una solución habitacional y, en especial, a las mujeres, que fueron activadas políticamente por el gobierno a través de los centros de madres. Esto indujo a la izquierda, tradicional y armada, a disputar esas nuevas bases sociales, acentuando la politización y las tomas (Tinsman, 2009; Garcés, 2005). En ese sentido, los estallidos se desterritorializaron, porque excedieron a las áreas económicas estratégicas, lo que relativizó la capacidad neutralizadora de las Zonas de Emergencia y la aplicabilidad de la Ley de Seguridad Interior, a pesar de que siguieron usándose. En ese contexto, se abrió un intersticio para repensar el papel de las Fuerzas Armadas, aunque, en general, la policía siguió siendo la encargada de esas tareas.

En efecto, el gobierno del democratacristiano Eduardo Frei policializó el conflicto, esto es, amplió la utilización de Carabineros para enfrentar a la movilizada sociedad chilena, específicamente el "Grupo Móvil”, que fue la unidad encargada de contener la protesta social, por lo que se consideró "la conveniencia de contar en todo momento con personal que pueda hacer frente adecuadamente a los movimientos sociales que de un modo y otro puedan alterar el orden público [lo que] movió a la Dirección General a dar una nueva disposición a la 19a comisaría 'Móvil', elevándola a la categoría de Grupo” (Plaza, 2018). En 1967 y 1968 se crearon "Grupos Móviles" en Concepción y Valparaíso, aumentando sus dotaciones 
hasta 1970, con un claro perfil antidisturbios. ${ }^{29}$ Carabineros "modernizó" su armamento, con lanzagases y distintos tipos de granadas; hacia 1970 contaban con cascos protectores, máscaras antigases y escudos, así como chalecos antibalas. Todo este armamento era producto de la influencia estadounidense y el Programa de Seguridad Pública, mientras la Police Academy de Washington (dependiente de la Agencia para el Desarrollo Internacional) prestó asesoría a Carabineros y una centena de policías chilenos viajaron a Estados Unidos y Panamá, donde realizaron cursos sobre el papel de la policía en la seguridad nacional e interna, la inteligencia policial, la contrainsurgencia y el comunismo como amenaza en América Latina (Maldonado y Águila, 1996). Esta influencia estadounidense, sin embargo, no fue la responsable de la policialización ocurrida, que, como señalamos, respondía a conflictos internos, pero sí acentuó su violencia.

A ella se agregó la utilización de los militares en situación de huelga, como ocurrió a comienzos de 1966 en el yacimiento de cobre de El Salvador, en medio de la paralización general declarada por la Confederación de Trabajadores del Cobre, produciéndose reiterados enfrentamientos con carabineros. El gobierno decretó Zona de Emergencia. Como en otras ocasiones, el oficial a cargo prohibió el uso y porte de armas, las reuniones en lugares públicos, pero tras la orden gubernativa de reanudación de faenas -en marzo de 1966- los militares avanzaron sobre el local sindical, lanzando bombas lacrimógenas y disparando, provocando la muerte de más de una decena de trabajadores (Cerda, 2014). La represión en El Salvador fue un hito, pues escapó al carácter que tenían las Zonas de Emergencia; la izquierda exigió aclarar lo sucedido, condicionando el ascenso de varios oficiales a grados superiores a la investigación de sus actuaciones como jefes de Zona.

Mientras la izquierda rechazó cualquier intervención militar, la derecha la legitimó: "La ciudadanía... señala con claridad a los responsables y solidariza plenamente con el gobierno y con las Fuerzas Armadas y de Orden que están cumpliendo su deber. Las víctimas provocadas por los autores de la subversión son un dramático testimonio de la necesidad de que el gobierno libere al país del cerco de agitación, que busca la violencia, y la destrucción de vidas y bienes”." Conservadores y liberales coincidieron en que las Fuerzas Armadas obedecían al Ejecutivo y cumplían con su deber de mantener el orden interno, pues "constituyen el poder institucional de la nación... Ningún Estado democrático puede cumplir sus finalidades si no tiene el respaldo del poder institucional de la nación, que está formado por el conjunto de las Fuerzas Armadas”. ${ }^{31}$ El gobierno, por su parte, legitimó lo ocurrido: "El gobierno no está enfrentando a los trabajadores sino a la acción contrarrevolucionaria (sic) de grupos extremistas organizados... Las Fuerzas Armadas estaban cumpliendo con su deber" ${ }^{32}$

29 BN, (1989), Revista de Carabineros, Santiago, Núm. 412, p.12

30 BN, (12 de marzo de 1966), El Mercurio, Santiago, p.3.

31 BN, (1 de diciembre de 1969), El Diario llustrado, Santiago, p.3.

32 BN, (12 de marzo de 1966), La Nación, Santiago, p. 5. 
El proceso de agotamiento de los dispositivos coercitivos existentes se aceleró con el triunfo de Salvador Allende y la Unidad Popular en 1970, el cual demostró que el diagnóstico de la izquierda respecto de la institucionalización, había sido correcto; la "Vía chilena al socialismo" no habría sido posible sin ella. Por lo mismo, se multiplicaron los sentidos de amenaza del empresariado, del desvencijado poder latifundista, de gran parte de la DC y de las derechas políticas y económicas. En el caso de la DC, la razón estuvo fundamentalmente en el anticomunismo de la gran mayoría de sus militantes y sus temores ante la influencia soviética y cubana, a pesar de lo cual estuvieron dispuestos a votar por Allende en el Congreso, luego de obligarlo a firmar un Estatuto de Garantías Constitucionales, para asegurar que la UP respetaría las libertades públicas y no usaría su poder para instalar una dictadura.

A diferencia de Argentina, donde los grupos armados encarnaron el mayor reto, en Chile la amenaza se corporizó en el gran poder del Estado, existente en la institucionalidad, pero que hasta entonces no se había utilizado a su total capacidad, que abrió paso al socialismo: Allende nacionalizó la gran minería del cobre, el sistema bancario, el gran comercio e industria y aplicó a toda su capacidad la ley de reforma agraria, entregando tierra a los campesinos. Éstos, ya movilizados, liquidaron el orden señorial y los obreros pasaron a controlar muchas unidades productivas. Una revolución "por arriba", desde la institucionalidad, y otra "por abajo", desde la sociedad, pusieron al derecho de propiedad y el papel social del empresario en jaque, provocando una "crisis de dominación celular", la más grave para el capitalismo (O’Donnell, 1982; Winn, 2004). Lo que hasta entonces había sido solo un peligro potencial, se transformó en acto. A diferencia de sus antecesores, Allende se negó a usar los dispositivos represivos del Estado para impedir las tomas, exigido por la derecha y la DC, haciendo evidente la obsolescencia del aparato coercitivo policial y legal.

La experiencia de la UP terminó de quebrar los débiles consensos en torno a la institucionalidad de 1925, porque ésta posibilitó el triunfo marxista, fue direccionada a superar el capitalismo y vitalizó el horizonte socialista. Todos los anticomunismos se activaron desde el 4 de septiembre de 1970.

Si bien, la DC compartía parte importante del programa de la UP, rechazó su implementación desde el Ejecutivo, exigió su discusión en el Congreso, demanda que provocó resistencias en la UP y agrió las relaciones. La ruptura decisiva ocurrió con el asesinato, en junio de 1971, de quien fuera ministro del Interior de Frei, a manos de un partido de izquierda radicalizado. A partir de entonces, la DC se desplazó a una alianza con la derecha y la superación del sistema coercitivo existente, demandando su militarización.

Oponiendo un proyecto de orden interno alternativo al de Allende, que mantenía la autoridad presidencial, la DC propuso el desarme de los grupos de izquierda que revindicaban la vía armada, entregando la incautación de las armas a las Fuerzas Armadas, la investigación a la inteligencia militar, y no a Investigaciones, a quien correspondía. Esta ofensiva derivó en la aprobación de la Ley de 
Control de Armas, que propuso modificar la ley de Seguridad Interior del Estado de 1958, para entregar a esas entidades atribuciones en el orden interno: "En la actualidad -señaló el demócrata-cristiano Juan de Dios Carmona- el control de las armas corresponde tanto a las Fuerzas Armadas como a las autoridades políticas civiles... es absolutamente necesario, que en las actuales circunstancias se lleve un control único por medio de las Fuerzas Armadas, que por disposición constitucional constituyen la fuerza pública" ${ }^{33}$ El objetivo era quitar al Ejecutivo la facultad exclusiva de invocar dicha ley y entregarla a numerosas autoridades de distinto rango: jueces, alcaldes, etc., autonomizando el poder militar, pues esa tarea quedaría entregada a sus valores y patrones de conducta, sin control civil. La ley fue aprobada en octubre de 1972.

Su potencialidad política pudo observarse claramente desde mediados de 1973, cuando fallaron todas las vías legales y de movilización para derrocar al gobierno de la UP, y una vez que las autoridades constitucionalistas de las Fuerzas Armadas fueron sacadas del mando. Tras el fallido intento de golpe del 29 de junio, la DC y la derecha presionaron por la aplicación de la Ley de control de armas, acusando al gobierno de estar ad portas de la instalación de una dictadura comunista, creando milicias populares. ${ }^{34}$ La fase final para el golpe requería de la autonomización militar en materia represiva, lo que solo podría lograrse, legalmente, a través de la Ley de Control de Armas, pues todos los otros estados de excepción y las fuerzas policiales, eran resorte del Ejecutivo.

Usando esa ley, desde julio de 1973 los allanamientos de fábricas y locales de gobierno, sindicatos y partidos de la Unidad Popular se sucedieron, en busca de supuestos arsenales denunciados por la oposición. La acción militar, a diferencia de lo que ocurría en las Zonas de Emergencia, estaba imbuida de las lógicas del enemigo interno y actuaba con gran violencia, como ocurrió en la Lanera Austral en Magallanes: "Con fuertes puntapiés y una violencia increíble notificaron el allanamiento... posteriormente se repartieron por toda la planta, obligando a los trabajadores a colocarse con las manos en la nuca para ser revisados uno por uno, ni siquiera se salvaron las mujeres" ${ }^{35}$ A comienzos de septiembre de 1973, se allanó el Centro de Producción, estatal, "Jorge Fernández”, ex fundo "Nehuentué", en la comuna de Puerto Saavedra, un operativo iniciado el 30 de agosto que se extendió hasta el 3 de septiembre, ordenado autónomamente por el Comandante del Regimiento Tucapel de Cautín y realizado por efectivos suyos, bajo la acusación de la existencia de arsenales, de una fábrica de granadas y de una escuela de guerrilla del MIR; se detuvo a 27 "extremistas", quienes permanecieron incomunicados. ${ }^{36}$ En opinión de la derecha "La Ley de Control de Armas ha sido el instrumento democrático puesto en manos de las Fuerzas Armadas para que procure el desarme de las organizaciones de cualquier orden y cualquier color político que constituyen una amenaza de violencia contra la

33 “Informe de la Comisión de Constitución, Legislación, Justicia y Reglamento”, BCN Boletín de Sesiones del Senado, sesión 18a, Anexo Documentos, 1972, pp.1186 y ss.

34 BN, (7 de julio de 1973), La Prensa, Santiago, p.11.

35 BN, (7 de agosto de 1973), El Diario Austral, Valdivia, p.1.

36 BN, (4 de septiembre de 1973), El Diario Austral, Valdivia, p.1. Véase también 2 de septiembre, p. 1. 
tranquilidad pública y la estabilidad institucional". ${ }^{37}$ En ese mismo criterio, se justificaba el papel represivo de las Fuerzas Armadas, sin que los civiles fijaran los métodos a utilizar: "lo que queda es que las Fuerzas Armadas intensifiquen las acciones realizadas para detectar sus arsenales, disolver los grupos armados y sancionarlos de acuerdo a la ley". ${ }^{38}$ Más aun, se incitaba a la población a delatar a personas y lugares supuestamente armados: "El dato, la denuncia a regidores y parlamentarios para que ellos puedan hacerlas llegar a las autoridades militares y judiciales que pueden hacer los requerimientos es hoy un acto patriótico", 39 sentenció el senador Carmona, haciendo un llamado a las mujeres, a los trabajadores, a los intelectuales, a los profesionales, a los militares, los campesinos, los pobladores, a los estudiantes universitarios a hacer esas denuncias. En una tónica similar, en agosto, fueron torturados un grupo de marineros acusados de entablar conversaciones con el MIR y socialistas para socavar la unidad y disciplina en los bajos escalafones de la Armada.

El tipo de represión militar que se observó en esos allanamientos escapaba a los dispositivos represivos anteriores y representó un anticipo de lo que sucedería a partir del golpe. Una nueva época comenzó.

\section{Conclusiones}

A nuestro juicio, las formas represivas estatales estuvieron en relación con el tipo de conflicto, el carácter de la amenaza y el peso de los factores políticos. En el caso de Chile, el conflicto estaba en el proyecto país: por un lado, la defensa de orgánicas gremiales y no sindicales, y un orden centrado económicamente en el mercado; y otro con importante intervencionismo estatal con efectos redistributivos; derechos ciudadanos amplios y un horizonte más igualitario; socialista, para unos, socialdemócrata, para otros. Aunque esta fractura pareció resolverse con la Constitución de 1925, que reconocía el intervencionismo estatal social y económico, los derechos sindicales de trabajadores urbanos y el pluralismo político-ideológico, ello no fue así, pues se deseaba su transformación, ya fuera hacia una mayor democratización o en un sentido autoritario y devolviendo al mercado una función determinante. Ello incidió en una lucha política intensa cuyo centro era la institucionalidad. Si bien la existencia de disensos es propia de la lucha política, la ausencia de acuerdos básicos, elementales, sobre las personas como sujetos de derechos, bloquea un orden democrático, introduciendo la idea de subversión, como amenaza al orden vigente. Ello conduce a dispositivos represivos que la neutralicen, pero al precio de coartar los derechos ciudadanos y desconocer la naturaleza de la política, como el espacio de la disputa, entregando la resolución del conflicto a agentes que tienen otras funciones sociales

37 BN, (22 de julio de 1973), El Diario Austral, Valdivia, p. 8.

38 BN, (14 de julio de 1973), La Prensa, Santiago, p. 5.

39 BN, (15 de julio de 1973), La Prensa, Santiago, p. 9. 
Considerando que la lucha se daba en el plano institucional, los aparatos de represión estatal fueron diseñados para enfrentar ese desafío: vigilar, informar sobre las actividades de sindicatos y dirigentes de izquierda, neutralizar el poder de las huelgas, distinguiendo entre agitadores y masa, es decir, los cabecillas reacios a subordinarse. Los dispositivos fueron leyes de seguridad interior -de excepción constitucional- y acción policial, con uso desproporcionado de la violencia, pues se enfrentaba con armas a huelguistas, que ejercían su derecho constitucional a la reunión, con resultados de heridos y muertos. Las Fuerzas Armadas actuaban en Zonas de Emergencia, pero bajo liderazgo civil y sin tareas de represión física, sino de coartación de libertades civiles y políticas. No eran aparatos dirigidos a exterminar, ni a torturar, sino a neutralizar, con efectos transitorios.

En los años sesenta y, particularmente, durante la Unidad Popular, ese precario equilibrio se rompió, porque las tensiones proyectuales se agudizaron, el Estado acrecentó su intervencionismo y se puso fin a la marginación política de campesinos y pobres urbanos, modificando el carácter de la amenaza, ahora personificada en una movilización popular generalizada y un Ejecutivo mucho más autonomizado. En ese contexto, las derechas y una gran mayoría de la Democracia Cristiana vieron en el poder militar, independizado, el mecanismo estatal requerido para neutralizar la nueva subversión, el cual utilizaría métodos bélicos, ajenos a lo que fue la lucha política con anterioridad al golpe, a pesar de que esa amenaza no era armada. Pero, el poder del Ejecutivo y su prescindencia represiva ante el reto al capital, hicieron ver como obsoletos los dispositivos policiales y de excepción, militarizándolos.

Los factores internacionales favorecieron una militarización del conflicto, pero no determinaron las trayectorias ocurridas, que respondían fundamentalmente a un conflicto interno. La interamericanización de la subversión facilitó los discursos en pro de la exclusión, la modificación del papel de las Fuerzas Armadas y sus métodos, pero ellas fueron opciones de los sujetos, no meras digitaciones imperiales. 


\section{Bibliografía}

"About, I. y Denis, V. (2011). Historia de la identificación de las personas. Barcelona: Ariel.

" Agamben, G. (2003). Estado de excepción. Buenos Aires: Adriana Hidalgo Editores.

" Álvarez, R. (2003). Desde las sombras. Una historia de la clandestinidad comunista. Santiago: Lom.

" Bawden, J. (2016). The Pinochet Generation. The Chilean Military in Twentieth Century, Tuscaloosa: University of Alabama.

"Bohoslavsky, E. (2011). Del anticomunismo de los antiguos comparado con el de los modernos: razones y pasiones de las derechas chilenas (1932-1973)". Buenos Aires: Observatorio Latinoamericano, núm. 8, pp. 48-64.

" Casals, M. (2016). La creación de la amenaza roja. Del surgimiento del anticomunismo en Chile a la 'campaña del terror' de 1964. Santiago: Lom.

"Cavarozzi, M. (2017). Los sótanos de la democracia, 1938-1964. Las esferas de protección de los empresarios industriales: la CORFO, represión a los obreros y la inflación. Santiago: Lom.

" Cerda, R. (2014). la masacre de El Salvador. Santiago: Sartaña.

" Constazo, G. (2009). Los indeseables. Las leyes de Residencia y de Defensa Social, Buenos Aires, Madre Selva

"Devés, E. (1987). Los que van a morir te saludan. Historia de una masacre, Escuela Santa María, Iquique, 1907. Santiago: Editorial Documentas.

"Fernández Darraz, E. (2003). Estado y sociedad en Chile, 1891-1931. El Estado excluyente, la lógica estatal oligárquica y la formación de la sociedad. Santiago: Lom.

"Fermandois, J. (2005). Mundo y fin de mundo. Santiago: Ediciones Universidad Católica de Chile.

"Fessler, D. (2015). El delito con rostro. Los comienzos de la identificación de delincuentes en Uruguay, Passagens. Revista internacional de historia política e cultura jurídica, 7 (1).

"Franco, M. (2019). El estado de excepción a comienzos del siglo XX: de la cuestión obrera a la cuestión nacional", Avances del Cesor, , XIV (20), pp.29-51.

"Franco, M. (2012). Un enemigo para la nación. Buenos Aires: Fondo de Cultura Económica.

" Frühling, H. (1982). Fuerzas Armadas, orden interno y derechos humanos. En Frülingh, H., Portales, C., Varas, A. Estado y Fuerzas Armadas en el proceso político chileno. Santiago: FLACSO.

" Garcés, M. (2005). “Construyendo las poblaciones. El movimento de pobladores durante la UP" en Julio Pinto (Editor) Cuando hicimos historia. La experiencia de la Unidad Popular. Santiago: Lom.

" García Ferrari, M. y Galeano, D. (2015). Cartografía del Bertillonaje. Circuitos de difusión, usos y resistencias al sistema antropométrico en América Latina", en Daniel Palma (Editor) Delincuentes, policías y justicia. América Latina, siglo XIX y XX, Santiago: Ediciones Universidad Alberto Hurtado.

" Gómez, J. C. (2004). La frontera de la democracia. Santiago: Lom. 
"Huneeus, C. (2009). La Guerra Fría chilena. Gabriel González Videla y la Ley Maldita. Santiago: Debate.

" Iglesias, M. (2010). "La excepción y la regla. Estado, partidos políticos y Medidas Prontas de Seguridad en Uruguay, 1946-1963", Tesis de Maestría, Buenos Aires, Universidad Nacional de General Sarmiento.

" Jiménez, F. (2010). Los estados de excepción constitucional en Chile. Concepción: Universidad Católica de la Santísima Concepción.

" Kierszenbaum, L. (2013). “Estado peligroso" y Medidas prontas de Seguridad: violencia estatal bajo democracia (1945-1968), Contemporánea, núm. 3, pp. 97-114.

" Loveman, B. (2016). The Political Architecture of Dictatorship: Chile before september 11, 1973, Radical History, 12 (24), pp. 11-41.

" Loveman, B. y Lira, E. (1999). Las suaves cenizas del olvido. Vía chilena de reconciliación política, 1814-1932. Santiago: Lom.

" Loveman, B. y Lira, E. (2000). Las ardientes cenizas del olvido. Vía chilena de reconciliación política, 1932-1994. Santiago: Lom.

" Loveman, B. y Lira, E. (2013). Poder Judicial y conflictos políticos (1925-1958). Santiago: Lom.

" Lvovich, D. (2016). La Semana Trágica en clave transnacional en J.B. Bertonha y Ernesto Bohoslavsky (editores) Circule por la derecha. Buenos Aires: Ediciones UNGS.

" Maldonado, C. (1990). Los Carabineros de Chile: historia de una policía militarizada. Revista Nórdica de Estudios Latinoamericanos, XX, 3.

" Maldonado, C. y Águila, E. (1996). Orden público en el Chile del siglo XX: Trayectoria de una policía militarizada, en Peter Waldmann (Editor) Justicia en la calle. Ensayos sobre la policía en América Latina, Buenos Aires: Konrad- Adenauer- Stiftung; ISLA Universität Augsburg; CIEDLA.

" Moulian, T. (2006). Fracturas. De Pedro Aguirre Cerda a Salvador Allende (1938-1973), Santiago, Lom

" Moulian, T. (1982). Desarrollo político y Estado de compromiso: desajuste y crisis estatal en Chile, Santiago, Estudios Cieplan, No.8.

" O’Donnell, G. (1982). El Estado burocrático-autoritario. Buenos Aires: Belgrano.

" Patto Sá Motta, R. (2002). Em guarda contra o perigo vermelho. São Paulo: Editora Perspectiva/FAPESP.

" Plaza, C. (s/f). Carabineros de Chile: seguridad interna y policialización de la protesta (1946-1970), manuscrito inédito.

" Pinto, J. (2006). ¿Y la historia les dio la razón? El MIR en dictadura (1973-1981) en Valdivia, V., Álvarez, R. y Pinto J., Su revolución contra nuestra revolución. Izquierdas y derechas en el Chile de Pinochet. Santiago: Lom.

" Portales, C. (1982). Instituciones políticas y Fuerzas Armadas en Frühling, Portales y Varas, Estado y Fuerzas Armadas. Santiago: Flacso.

" Rojas, J. (1993). La dictadura de Ibáñez y los sindicatos (1927-1931). Santiago: Lom.

"Romano, S. (2012). Seguridad hemisférica, asistencia y democracia en los inicios de la Guerra Fría, Bogotá, Revista de Relaciones Internacionales, Estrategia y Seguridad, vol.7, No.1.

"Salgado, A. (2016). Exemplary Comrades: The Public and Private Life of Communist in Twentieth-Century Chile, PhD Diss, Columbia University. 
"Suriano, J. (1989-90). El Estado argentino frente a los trabajadores urbanos: política social y represión, 1880-1916, Anuario, No.14, Rosario.

"Tinsmann, H. (2009). La tierra para el que la trabaja. Género, sexualidad y movimientos campesinos en la reforma agraria chilena. Santiago: Lom.

"Valdivia, V. (2017). Subversión, coerción y consenso. Creando el Chile del siglo XX (19181938). Santiago: Lom.

"Valdivia, V. (2019). La derecha conservadora y liberal ante el asedio del comunismo y la derecha radical (1918-1932) en Bohoslavsky, E.; Jorge, D. y Lida, C. (editores) Las derechas iberoamericanas, desde el final de la Primera Guerra hasta la Gran Depresión, México, Colegio de México, pp.211-246.

"Valdivia, V. (2020). Pisagua, 1948. Anticomunismo y militarización política en Chile,. Santiago: Lom (en prensa).

"Valdivia, V. y Pinto, J. (2020). Repensando a la derecha chilena, 1925-1932, Istoriya, Moscú, 5.

"Varas, A., Agüero, F. y Bustamante, F. (1980). Chile, democracia, Fuerzas Armadas, Santiago: Flacso.

"Winn, Peter (2004). Tejedores de revolución, Santiago: Lom.

" Yáñez, J. C (2003). Estado, consenso y crisis social. Santiago: Dirección de Biblioteca, Archivos y Museos.

"Zanatta, L. (2011). Eva Perón. Una biografía política, Buenos Aires: Sudamericana. 